\title{
Diurnal Air Quality Monitoring in Khumaltar Area, Lalitpur, Nepal
}

\author{
Sujen Man Shrestha, Kanchan Thapa and Tista Prasai Joshi
}

\begin{abstract}
Air pollution is becoming a serious matter of concern from different aspects of our lives. It adversely affects the well being of the individuals or cause damages to properties. Pollutants identification requires measurements by standard methods of sampling and analysis. In this study, monitoring of TSP, $\mathrm{PM}_{10}, \mathrm{SO}_{2}$ and $\mathrm{NO}_{2}$ were performed during the months of April - August, 2008 by using high volume sampler, i. e. Envirotech APM 451 Model. Four hours (11:00 am to 3:00 pm) of monitoring for $\mathrm{SO}_{2}$ and $\mathrm{NO}_{2}, 24$ hours of monitoring for TSP and $\mathrm{PM}_{10}$ were carried out. $\mathrm{SO}_{2}$ concentration ranged from $4.8 \mu \mathrm{g} / \mathrm{m}^{3}$ to $20.5 \mu \mathrm{g} / \mathrm{m}^{3}$ and $\mathrm{NO}_{2}$ concentration ranged from $1.2 \mu \mathrm{g} / \mathrm{m}^{3}$ to $8.8 \mu \mathrm{g} / \mathrm{m}^{3}$ for four hour monitoring period. TSP concentration ranged from $24.7 \mu \mathrm{g} / \mathrm{m}^{3}$ to $82.0 \mu \mathrm{g} / \mathrm{m}^{3}$ whereas $\mathrm{PM}_{10}$ concentration ranged from $25.4 \mu \mathrm{g} / \mathrm{m}^{3}$ to $152.4 \mu \mathrm{g} / \mathrm{m}^{3}$ for 24 hours of monitoring. Present study concluded that the air quality of Khumaltar area in Lalitpur, Nepal met WHO as well as NAAQS standards during the study period. Nepalese cities/towns have always been thought to be serious in terms of particulate matter pollution but consideration of the trend of gasesous pollutants emitted from vehicle exhaust is recommended for future research.
\end{abstract}

Keywords: Air Quality Monitoring, Nitrogen dioxide $\left(\mathrm{NO}_{2}\right)$, Particulate Matter (PM), Sulfur dioxide $\left(\mathrm{SO}_{2}\right)$, Total Suspended Particle (TSP), Nepal

\section{Introduction}

$A$ ir pollution is a phenomenon of worsening the Aambient air quality by the addition of pollutants from various natural and anthropogenic activities that can cause a major health problem, affecting developed and developing nations alike around the globe and resulting in damage to living beings and the environment. Epidemiological studies suggest that there is an association between particulate pollution and respiratory illness, also is responsible for number of cardiovascular diseases, respiratory diseases and associated mortality and morbidities (Seaton A. et al, 1995).

Air pollution can occur either from or within the environment itself. Pollutants emitted by a source directly into the atmosphere is called primary air pollutants and those formed later in the atmosphere is called secondary pollutants. Besides the physical state of pollutants, it is important to consider the geographical location and distribution of sources. Sulfur dioxide, oxides of nitrogen, oxides of carbon, volatile organic compounds can be regarded as primary pollutants. On geographical scale, sources like road transport, stationary combustion sources and natural sources can be considered. Secondary pollutants result from chemical reactions of primary pollutants in the atmosphere often in presence of natural oxygen and water of environment (WHO 2005).

Particulate Matter (PM) is the general term used for a mixture of solid particles and liquid droplets found in the air. These particles, which come in a wide range of sizes, may be emitted directly by a source or be formed in the atmosphere. Total Suspended Particle (TSP) refers to the aggregate of solid or liquid matter in air. Such particles vary in size (up to 45 micrometers in diameter) and may remain suspended in the air a few seconds to several months. Particulate matter
(PM) is solid matter or liquid droplets originating from smoke, dust, fly ash or condensing vapors that can be suspended in the air for long periods of time. Particulate matter in air with aerodynamic diameters less than 10 micrometers is $\mathrm{PM}_{10} \cdot \mathrm{PM}_{10}$ appears to represent essentially all of the particulate emissions from transportation sources and most of the emissions in the other traditional categories. Sulfur dioxide is formed from the combustion of sulfur-containing fuels. Typically, large coal-fired combustion sources (e.g., power plants) are the potential sources of concern. $\mathrm{NO}_{2}$ is a gas formed during combustion from the reaction of oxygen and nitrogen (Note: $\mathrm{NO}_{2}$ is derived from the nitrogen in the air, while $\mathrm{SO}_{2}$ is formed from fuel-derived sulfur). It is emitted from both mobile and stationary sources (EPA 2003).

Monitoring and assessment of air pollution load from different sources and their impacts on the affected population and on the environment are the pre-requisites for development of strategy and action plans. Various guidelines, acts and regulations have been adopted to maintain ambient air less polluted in Nepal (NHRC 2009). Ambient air refers to the air close to the ground that is in direct contact with the living world (WHO 2008). In order to determine the existing quality of air, evaluation of effectiveness of pollution mitigation measure, current gaps, strategies and develop new technologies ambient air quality monitoring are performed (Shrestha B. 2001). It is also important to consider the nature of pollutants to monitor, various technologies of monitoring and location where the monitoring is planned ( $\mathrm{CPCB}$ 2003).

Since Nepal can't afford advanced, sophisticated and expensive technologies, a preliminary air quality survey is essential before the implementation of air quality management program for setting up the costeffective network of continuous monitoring stations (Graves R. J. et. al, 1981). This study describes the 
distribution of air pollutants concentration monitored at Khumaltar station in Lalitpur District in Nepal. The Khumaltar station was chosen due to its proximity to Patan Industrial Area, and also to residential areas of Khumaltar, Satdobato and Hattiban. Khumaltar is located at $27^{\circ} 39^{\prime} 24.61^{\prime \prime}$ north latitude and $85^{\circ} 19^{\prime}$ 40.47" east longitude, in the south of Kathmandu at a distance of about Sampling $6 \mathrm{~km}$. The station was selected for being a residential area with minimum number of tall buildings. Thus, because of prevailing type of emission sources, air pollutant concentration in every particular area might differ. This study considered Total Suspended Particles (TSP), respirable suspended particulate matter $\left(\mathrm{PM}_{10}\right)$, sulfur dioxide and nitrogen dioxide for monitoring purpose. It would also be helpful in providing the baseline data on air quality of the selected study area during a particular year and for comparison with air pollution status of other areas of Kathmandu valley.

\section{Methodology}

The study was carried out to monitor air quality during April to August 2008 in Khumaltar Lalitpur by using high volume sampler, i.e. Envirotech APM 451 Model. The determined pollutants were compared with WHO standard (WHO 2005) as well as National Ambient Air Quality standards (MoSTE 2003) for air quality. The air quality monitoring period was chosen as 4 hours in a day from 11:00 am to 3:00 pm for $\mathrm{SO}_{2}$ and $\mathrm{NO}_{2}$. The monitoring of total suspended particles and $\mathrm{PM}_{10}$ was fixed as 24 hours.

This sampler (designed based on NEERI, Nagpur, Technology) separates TSP and respirable fraction (i.e. particle size less than 10 microns) of suspended particulate matter (RSPM) and thus helps in estimation of both TSP and $\mathrm{PM}_{10}$ concentrations. This instrument has provision for incorporation of gaseous sampling unit for simultaneously monitoring gaseous pollutants like $\mathrm{SO}_{2}$ and $\mathrm{NO}_{2}$ present in ambient air. The sampling (Manual) for TSP concentration was determined by using gravimetric analysis and the $\mathrm{PM}_{10}$ concentration has been done using Whattman GF/A glass fiber filters. The analytical procedure for determination of TSP and $\mathrm{PM}_{10}$ is as per Bureau of Indian standards (BIS) given by methods for measurement of Air Quality (BIS 1985). The sampling for $\mathrm{NO}_{2}$ has been done using sodium hydroxide as absorbing medium and the $\mathrm{NO}_{2}$ concentration is determined using Colorimetric analysis by UV-V is Spectrophotometer. The analytical procedure, BIS: 5182, Part 10, 1985, for determination of $\mathrm{NO}_{2}$ is as per Bureau of Indian Standards (BIS) given by methods for measurement of Air Quality. The sampling for $\mathrm{SO}_{2}$ has been done using TCM solution in an absorber and collects the sample at 0.5 litre/minute for 4 hours and the $\mathrm{SO}_{2}$ concentration is determined, using Colorimetric analysis by UV-Vis Spectrophotometer. The analytical procedure for determination of $\mathrm{SO}_{2}$ is as per BIS given by methods for measurement of Air Quality.

\begin{tabular}{|c|l|}
\hline \multicolumn{2}{|l|}{ Method of Analysis } \\
$\begin{array}{c}\text { The air quality parameters are analyses as per BIS-5182 - Method of measurement of } \\
\text { pollution }\end{array}$ \\
\hline $\mathrm{SO}_{2}$ & $\begin{array}{l}\text { Modified West-Gacke method. Absorbed in tetrachloromercurate (TCM) } \\
\text { solution and the color producing reagent is pararosalinine (BIS-5182, Part IV) }\end{array}$ \\
\hline $\mathrm{NO}_{2}$ & $\begin{array}{l}\text { Jacobs-Hochheiser Arsenite, } \mathrm{NO}_{2} \text { is absorbed in an azo-dye forming reagent. } \\
\text { (IS-5182, Part X) }\end{array}$ \\
\hline $\mathrm{TSP}^{\mathrm{N}}$ & Gravimetric Analysis (IS-5182, Part-II) \\
\hline $\mathrm{PM}_{10}$ & Gravimetric analysis, Whattman GF/A filter (PM10) \\
\hline
\end{tabular}

ch APM 451 Respirable Dust Sampler (India made) for TSP, $\mathrm{PM}_{10}$ Envirotech APM 451 Respirable Dust Sampler (India made) for TSP, $\mathrm{PM}_{10}$ $\mathrm{SO}_{2}, \mathrm{NO}_{2}$. Flow rate: $0.8 \mathrm{~m}^{3} / \mathrm{min}$. (TSP, $\mathrm{PM}_{10}$ ); $0.5 \mathrm{~m}^{3} / \mathrm{min}_{\mathrm{SO}_{2}}, \mathrm{NO}_{2}$. The samples were $24 \mathrm{hr}$. for TSP, $\mathrm{PM}_{10}$ and $4 \mathrm{hr}$. for $\mathrm{SO}_{2}, \mathrm{NO}_{2}$.

Table 1: Monitoring methods used for air quality monitoring in Khumaltar, Lalitpur, Nepal

\begin{tabular}{|c|c|c|}
\hline Pollutant & NAAQS 2003 & WHO 2005 \\
\hline TSP & $\begin{array}{l}230 \mu \mathrm{g} / \mathrm{m}^{3} 24 \text { hours } \\
\text { mean }\end{array}$ & NA \\
\hline $\mathrm{PM}_{10}$ & $\begin{array}{l}120 \mu \mathrm{g} / \mathrm{m}^{3} 24 \text { hours } \\
\text { mean }\end{array}$ & $\begin{array}{l}20 \mu \mathrm{gg} / \mathrm{m}^{3} \text { annual mean } \\
50 \mu \mathrm{g} / \mathrm{m}^{3} \text { 24-hour mean }\end{array}$ \\
\hline $\mathrm{SO}_{2}$ & $\begin{array}{l}50 \mu \mathrm{g} / \mathrm{m}^{3} \text { Annual } \\
\text { mean } \\
70 \mu \mathrm{g} / \mathrm{m}^{3} 24 \text { hours } \\
\text { mean }\end{array}$ & $\begin{array}{l}20 \mu \mathrm{gg} / \mathrm{m}^{3} \text { 24-hour mean } \\
500 \mu \mathrm{g} / \mathrm{m}^{3} 10 \text {-minute } \\
\text { mean }\end{array}$ \\
\hline $\mathrm{NO}_{2}$ & $\begin{array}{l}40 \mu \mathrm{g} / \mathrm{m}^{3} \text { Annual } \\
\text { mean } \\
80 \mu \mathrm{g} / \mathrm{m}^{3} 24 \text { hours } \\
\text { Mean }\end{array}$ & $\begin{array}{l}40 \mu \mathrm{gg} / \mathrm{m}^{3} \text { annual mean } \\
200 \mu \mathrm{g} / \mathrm{m}^{3} \text { 1-hour mean }\end{array}$ \\
\hline
\end{tabular}

Table 2: Air quality standards (WHO 2005) and National Ambient Air Quality Standards (MoSTE 2003)

\section{Results and Discussion}

The total number of observations taken in the station was 7 for TSP and $\mathrm{PM}_{10}$ out of which the number in which the TSP and PM10 concentration level (Figure 1 and 2) exceeded the permissible limit (Table 2) is 1 in July for TSP and in August for $\mathrm{PM}_{10}$. The data on TSP were largely replaced by $\mathrm{PM}_{10}$ standard from 1987 onward (EPA 1995). PM $_{10}$ was produced largely by industrial and automobile exhaust, and was easily re-suspended into the lower atmosphere by vehicular traffic. (B. I. S. 1985; Sah, R. C. 2003; Pokhrel A. K. and Sharma, B. K. 1998 and URBAIR 1997). Khumaltar areas lies close to Patan Industrial areas and few brick kiln. The use of kerosene-burning stove for cooking purpose by the resident of Kathmandu is also responsible for increased status of $\mathrm{PM}_{10}$ (Devkota SR 1992). Rapid urbanization, industrialization, and poor maintenance of roads are important causes of air pollution in the valley (SoE Nepal 2001). 


\begin{tabular}{|c|c|c|c|c|}
\hline Months & $\begin{array}{c}\text { TSP }(\mu \mathrm{g} / \\
\left.\mathbf{m}^{\mathbf{3}}\right)\end{array}$ & $\begin{array}{c}\mathbf{P M}_{\mathbf{1 0}} \boldsymbol{\mu g} / \\
\mathbf{~ m}^{\mathbf{3}}\end{array}$ & $\begin{array}{c}\mathbf{S O}_{\mathbf{2}} \boldsymbol{\mu g} / \\
\mathbf{~ m}^{\mathbf{3}}\end{array}$ & $\begin{array}{c}\mathbf{N O}_{\mathbf{2}} \\
\mu \mathrm{g} / \mathbf{m}^{\mathbf{3}}\end{array}$ \\
\hline April & 33.9 & 25.4 & 20.5 & $\mathrm{ND}$ \\
\hline April & 25.4 & - & 11.8 & $\mathrm{ND}$ \\
\hline May & 39.0 & 25.5 & 14.4 & 1.7 \\
\hline May & - & 67.8 & 15.3 & 5.3 \\
\hline May & - & - & 12.0 & 1.2 \\
\hline May & - & - & 11.3 & 8.8 \\
\hline June & 24.7 & 33.9 & 11.1 & 5.7 \\
\hline July & 32.9 & 84.7 & 12.2 & - \\
\hline July & 175.3 & 93.2 & 13.1 & 1.8 \\
\hline July & - & 110.1 & 5.9 & 2.3 \\
\hline July & - & - & 10.0 & 4.9 \\
\hline July & - & - & 9.6 & 3.6 \\
\hline July & - & - & 9.8 & 3.8 \\
\hline August & 82.0 & 152.4 & 4.8 & 4.6 \\
\hline August & - & - & - & 4.6 \\
\hline August & - & - & 6.5 & 2.4 \\
\hline
\end{tabular}

Table 3: Distribution of air quality parameters of different months of Khumaltar, Lalitpur, Nepal

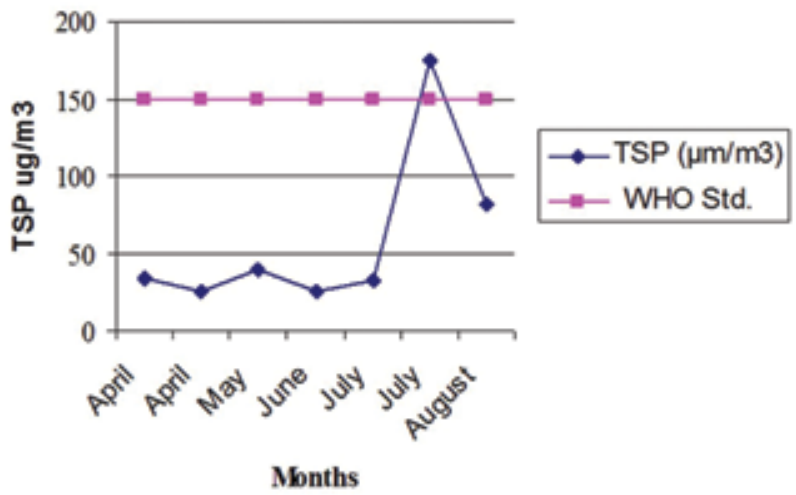

Figure 1: Average concentration of TSP for period of April-August 2008

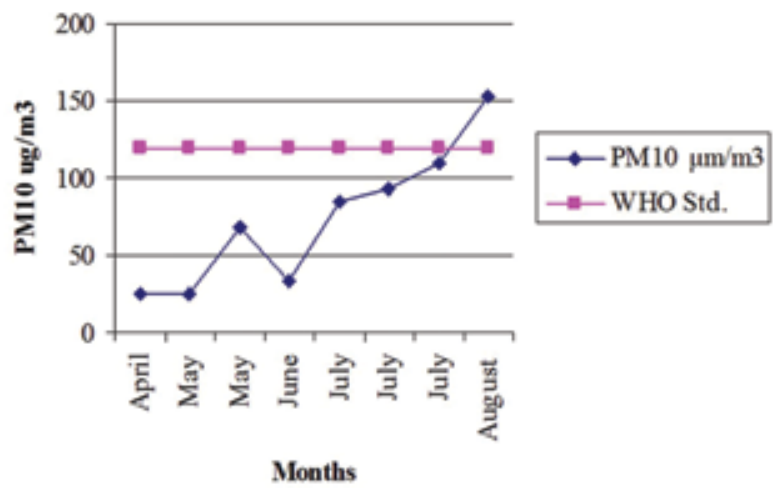

Figure 2: Average concentration of PM10 for the period of AprilAugust, 2008

The concentration range of $\mathrm{SO}_{2}$ observed was 4.8 $\mu \mathrm{g} / \mathrm{m}^{3}-20.5 \mu \mathrm{g} / \mathrm{m}^{3}$ and $\mathrm{NO}_{2}$ was observed $1.2 \mu \mathrm{g} / \mathrm{m}^{3}$ - $8.8 \mu \mathrm{g} / \mathrm{m}$ for 15 observations in the study period. Though, the result did not show alarming state of $\mathrm{SO} 2$ and $\mathrm{NO}_{2}$. One reading of $\mathrm{SO}_{2}$ exceeded the WHO standards of global update but can be considered within the limit when compared with NAAQS, 2003.
The increasing trend of Total Suspended Particles and Particulate Matter could not be generalized since it is the opposite phenomenon of settling of PM during rainy season. This might be due to the low number of data considered and also due to other atmospheric phenomenon such as relative humidity, wind direction and temperature (Ramasamy J. et al, 2013; Feng X. and Wang S. 2012). Interestingly, the result showed decreasing status of $\mathrm{SO}_{2}$ and $\mathrm{NO}_{2}$ because of soluble nature of both pollutants in water (EPA 1999). Study also shows that weather influence precipitation, diffusion, accumulation and transport of particulate matter (Feng X. and Wang S. 2012) .These things are very much important in order to understand the nature of atmospheric pollutants. The data of TSP and $\mathrm{PM}_{10}$ were found to have exceeded the WHO concentration in the months of July and August, which may be due to influence of metrological parameters such as temperature, humidity and wind direction etc. The days selected for monitoring might have had high temperature, high humidity or high wind, effects of which were not considered in this data collection.

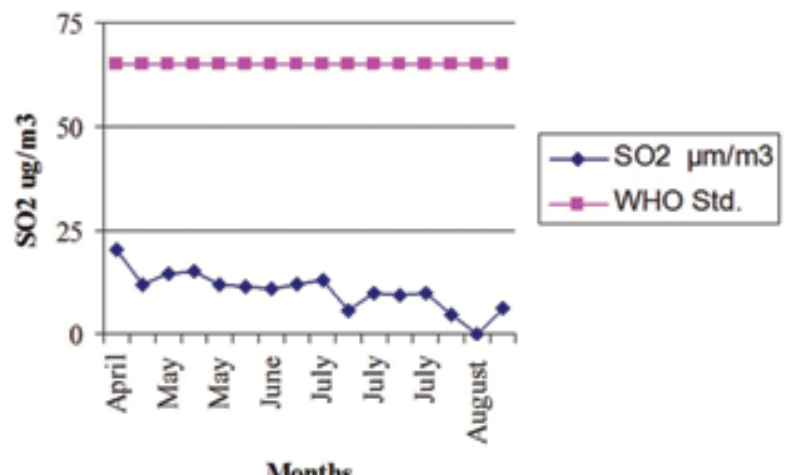

Figure 3: Average concentration of S02 for the period of AprilAugust, 2008

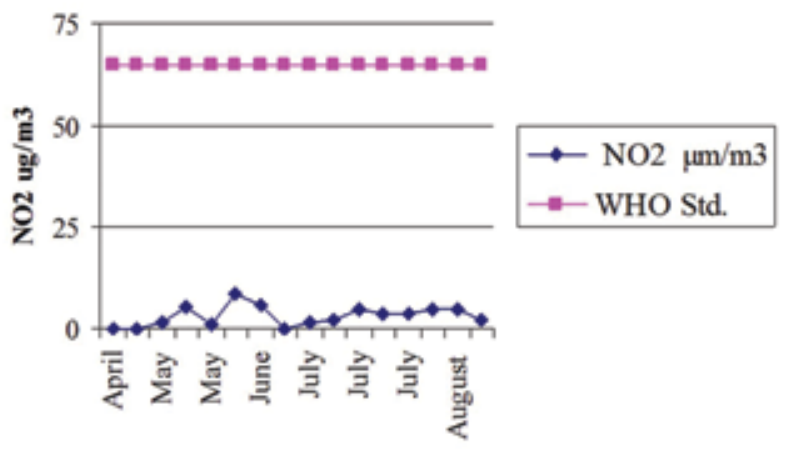

Months

Figure 4: Average concentration of NO2 for the period of AprilAugust, 2008

Nepal did not have any permanent monitoring network. The objective varied from one study to other though a number of studies had been conducted in the field of air pollution. The study largely depended on the various donor agencies as there was no specific national budget sanctioned for air pollution (SoE Nepal 1998). Nepal adopted the National Ambient Air Quality Standards (MoSTE 2003) as of July 4, 2003 
or NAAQS. And through the initiation of Ministry of Science, Technology and Environment in the cities of Kathmandu, Ambient Air Quality Monitoring (AQM) program was begun in 2002. The program started with six stations. At present, the six monitoring stations are located at Putali Sadak, Patan Hospital, Thamel, Bhaktapur, Kirtipur and Matsyagaon. These monitoring stations automatically collect samples of air over 24 hours, which are then analyzed for $\mathrm{PM}_{10}$. The data being generated from the six monitoring stations in Kathmandu gives a fairly good picture of the current status of air quality in the valley (MoSTE, 2006). Coming to the year of 2014 the ambient air quality monitoring was further degraded to compared to previous years, the air quality were found to cross the WHO and NAAQS guidelines values in Putalisadak (MaYA, 2014). According to published report of ICIMOD more than half of the emission was of PM and TSP, followed by $32 \%$ emission of Carbon monoxide, and rest $16 \%$ were of other emission. Major source of $\mathrm{SO}_{2}$ and $\mathrm{NO}_{2}$ and particulate matter is vehicle exhaust. Till 2009, an unpredicted increase of Vehicle rate was observed. In 2000, there was less than 200,000 registered vehicles but by 2009 there were half a million vehicles, among which sixty percent were registered in Kathmandu Valley (ICIMOD 2012) alone. Based on the data of vehicle emission, there might have been increased emissions of $\mathrm{NO}_{2}, \mathrm{SO}_{2}$ and CO.

It is not possible to conclude air quality status of Kathmandu valley based on temporal distribution of ambient concentrations of $\mathrm{PM}_{10}, \mathrm{SO}_{2} \& \mathrm{NO}_{2}$ measured in Khumaltar area but it can be very useful for further research. The result provided will be helpful as baseline data of air quality status of Kathmandu valley with reference to Khumaltar area of Lalitpur district.

There is no doubt that comprehensive annual air quality monitoring work is necessary to evaluate the effect of the environmental and topographical conditions on pollutants behavior. However, the information obtained by various organizations indicate the concentration level of pollutants that is posing threat to the ambient air quality. Among them, the works undertaken by KVVECP, NESS, Soil Test and DHM are useful for illustrating the trend in air pollution (CBS 1998).

\section{Conclusion}

The current study concluded that the air quality of Khumaltar areas met WHO as well as NAAQS standards during the study period. The increasing trends of gaseous air pollutants were obtained. The effects of other atmospheric phenomenon such as atmospheric wind speeds, wind direction, relative humidity were not considered in the study though effects of rain on $\mathrm{SO}_{2}$ and $\mathrm{NO} 2$ were clearly observed in the study period. A comprehensive air quality monitoring work is necessary to evaluate the air quality throughout the year. The present study was carried out in 2008, now concentration of these pollutants might have increased in the area. Though the study generated data for Khumaltar, it can be widely used for other studies conducted in Kathmandu valley for comparison purpose. Study covering representative sampling areas, high volume advance sampling techniques, and modern technology and through the multidisciplinary research team of research scientist adjusting the potential meteorological and atmospheric confounders are here by recommended in order to establish the evidence for health and environmental impacts of air pollution.

\section{Acknowledgement}

The authors would like to thank to Nepal Academy of Science and Technology (NAST) for providing financial and technical support to carry out this study. Sincere thanks to Chief of Faculty of Science and other colleagues.

Dr. Sujen Man Shrestha completed his $P h D$ in photochromisim in 2003 from Japan. He completed his MSc from Tribhuvan University in 1989. At present, he has been serving as Senior Scientific Officer in NAST since 1989. His research interests are on Air Quality, Water Quality, Microbiology, Environment, and Material Sciences.

Email: rainerx335@gmail.com

Mr. Kanchan Thapa has completed Master Degree in Public Health (MPH) from State University of Bangladesh (SUB) in 2012. He completed his Bachelor degree in Biology from Trichandra Campus in 2010. He was awarded with Assistant Research Fellowship from NAST in 2014. Mr. Thapa has years of teaching Public Health Programs, and research experiences. He was awarded the Young Scientist, 2015 on the occasion of First National Health and Population Scientist in Nepal from Nepal Health Research Council (NHRC).

Corresponding address: kanchanraj3@gmail.com

Ms. Tista Prasai Joshi has completed her M. Sc. in Microbiology from Tribhuvan University, Nepal. She has been serving in NAST since 2003. Currently, she is assigned as Scientific Officer in NAST. She has also years of experiences on microbiological research and teaching.

Email: tistaprasai@gmail.com

\section{References}

B. I. S. (Bureau of Indian Standards), 1985, Methods of Measurement of Air Quality, BIS: New Delhi, 5182, Part 4.

CBS (Central Bureau of Statistics), 1998, A Compendium of Environment Statistics of Nepal.

CPCB (Central Pollution Control Board), 2003, Guidelines for Ambient Air Quality Monitoring, (Ministry of Environment \& Forests, Govt. of India) Parivesh Bhawan, East Arjun Nagar.

Devkota, S. R., 1992, Energy utilization and air pollution in Kathmandu Valley, Nepal, Asian Institute of 
Technology, Bangkok.

EPA (Environmental Protection Agency), AIR Trends 1995, Air Trends Particulate Matter (PM-1O).

EPA (Environmental Protection Agency), 1999., Nitrogen Oxides (NOX), Why and How They Are Controlled. Clean Air Technology Center (MD-12) Information Transfer and Program Integration Division Office of Air Quality Planning and Standards: U.S. Environmental Protection Agency EPA-456/F-99o06R, November 1999.

EPA (Environmental Protection Agency), 2003, The Particle Pollution Report: Current Understanding of Air Quality and Emissions through 2003.

Feng X., Wang S.,. 2012, Influence of different weather events on concentrations of particulate matter with different sizes in Lanzhou, China, $J$ Environ Sci (China)., 24(4):665-74.

Graves. R. J., McGinnis, lee Jr., T.D, 1981, Air Monitoring Network Design: Ministry of Environment, Science and Technology, National Ambient Air Quality Standard (NAAQS) Monitoring Result in Kathmandu Valley, 2003-2004.

ICIMOD (International Centre for Integrated Mountain Development), 2012, Rapid Urban Assessment of Air Quality for Kathmandu, Nepal., ISBN 978929115 2674 (printed) 9789291152681 (electronic), LCCN 2012-323210.

MoSTE (Ministry of Environment, Science and Technology) 2003-2004, National Ambient Air Quality Standard (NAAQS) Monitoring Result in Kathmandu Valley.

MoSTE (Ministry of Environment, Science and Technology), 2006, Monthly Air Quality Monitoring Datasheet, Ministry of Science, Technology and Environment.

Pokhrel A. K., Sharma, B. K., 1998, A citizen's report on air pollution in Kathmandu: Children's health at risk, Society for Legal and Environmental
Analysis and Development Research and Japan Environment Corporation, Kathmandu, Nepal. LEADERS Nepal.

MaYA (Manav-kendrit Yatayat Abhiyan), 2014, Air Quality Status and Management in Kathmandu Valle, Clean Air Network Nepal/Clean Energy Nepal.

NHRC (Nepal Health Research Council), 2009, Situation Analysis of Environmental Health in Nepal, Ramshah Path, Kathmandu, Nepal.

Ramasamy J., Kumaravel, B., Palanivelraja S., Chockalingam M. P. Influence of

Temperature, Relative Humidity and Seasonal Variability on Ambient Air Quality in a Coastal Urban Area . International Journal of Atmospheric Sciences, 2013 (2013); 7. http://dx.doi.org/10.1155/2013/264046.

Sah, R. C., 2003, Nepal-Advocating and Enforcing Air Quality Standards in Nepal.

Seaton A., Godden D. , MacNee W., Donaldson K., 1995, Particulate air pollution and acute health effects, The Lancet 345(8943);176-178.

Shrestha, B., 2001, Air Pollution Status Kathmandu, Nepal, Air pollution in the Mega cities of Asia $3-5$ September 2001, Seoul, Korea.

SoE Nepal (Nepal: State of the Environment), 1998 and 2001.

URBAIR, 1997, Urban Air Quality Management Strategy in Asia: Kathmandu Valley $R$ e $p$ o $r t$, (Eds.), World Bank, World Bank Technical Paper No. 378.Workshop (URBAIR). Ministry of Industry, Kathmandu, Nepal.

WHO (World Health Organization) Global Update 2005, Air quality guidelines for particulate matter, ozone, nitrogen dioxide and sulfur dioxide, Summary of risk assessment.

WHO (World Health Organization), 2008, Children's Health and the Environment WHO Training Package for the Health Sector World Health Organization.

WHO, Air Quality Guidelines Global Update, 2005. 